\title{
Structural differences in mammal assemblages between savanna ecosystems of the Colombian Llanos
}

\author{
Dennis Castillo-Figueroaa ${ }^{1,2}$; Daniela Martínez-Medina ${ }^{1,3}$; Miguel E. Rodríguez-Posadaa, ${ }^{1,4}$ \& Sandra Bernal-Vergara ${ }^{1,5}$
}

\author{
${ }^{1}$ Fundación Reserva Natural La Palmita, Centro de Investigación, Grupo de Investigaciones \\ Territoriales para el Uso y Conservación de la Biodiversidad. Bogotá, Colombia. \\ ${ }^{2}$ ORCID: http://orcid.org/0000-0002-4584-0762. E-mail: dennis.castillof@gmail.com (corresponding author) \\ ${ }_{3}^{3}$ ORCID: http://orcid.org/0000-0002-9431-8399. E-mail: danimm087@gmail.com \\ ${ }^{4}$ ORCID: http://orcid.org/0000-0001-5670-3440. E-mail: director.cientifico@lapalmita.com.co \\ ${ }^{5}$ ORCID: http://orcid.org/0000-0002-8764-513X.E-mail: spbv08@gmail.com
}

\begin{abstract}
The Colombian Orinoquia region is characterized by a high diversity of mammals, which is associated with complex ecosystems that include large extensions of Neotropical savannas (known locally as "Llanos Orientales"). Despite accelerated anthropogenic transformations in savanna ecosystems, the knowledge to design effective conservation strategies, such as the distribution of mammal assemblages, is still lacking for this region. In this paper, we evaluate if assemblages of medium and large mammals (i.e., species richness, relative abundance and the contribution of the different trophic guilds) are homogeneous across the Colombian Llanos by comparing three savanna ecosystems: floodplains savannas associated with an Andean river, aeolian floodplains savannas and highland savannas. After a sampling effort of 3,150 camera trap/days, we recorded 16 mammal species from the three savanna ecosystems. We compared the three assemblages and their constituent trophic guilds by ANOSIM and SIMPER non-parametric permutation tests. The three assemblages differed in composition, structure and trophic guilds. The floodplains savannas, associated to an Andean river, present the highest diversity, contrastingly, the high-plain associated with the Guyanese Shield presents the lowest diversity. This pattern could be explained due to the greatest floristic diversity, complex vegetation structure and more fertile soils present in the riparian forests of the floodplains savannas, despite being the most anthropogenically transformed. The carnivores were the most variable category and herbivores were the most abundant. Our results show that the diversity of medium and large mammals is heterogeneously distributed in the Colombian Llanos. Therefore, it is necessary to implement targeted conservation strategies according to the characteristics, local fragility of each ecosystem in the territory and each species response by local conditions.
\end{abstract}

Key-Words. Neotropical savanna; Orinoco plains; Camera trapping; Medium- and large-sized mammals; Trophic guilds.

\section{INTRODUCTION}

The Neotropics contain about $30 \%$ of the total world mammalian diversity (Carrillo et al., 2015). Mammalian species display considerable impacts on the composition and dynamics of Neotropical ecosystems (Redford, 1992). Particularly, medium and large mammals (i.e., $>1 \mathrm{~kg}$ ) have key roles in ecosystem functioning such as seed dispersal (Acevedo-Quintero \& Zamora-Abrego, 2016), pollination (Carthew \& Foldinger, 1997; Steiner, 1981), seed predation (Logiudice \& Ostfeld, 2002), habitat modification (Giombini et al., 2016), and regulation of plant and animal species populations (Terborgh et al., 2001; Crooks \& Soulé, 1999).

Colombia holds the sixth highest level of mammal diversity globally and the third in the Neotropical region, with 518 species (Ramírez-
Chaves et al., 2016). This high diversity has been related to historical processes associated with its tropical position, topography and the high ecosystem diversity (Hernández-Camacho et al., 1992). In Colombia, five natural continental regions are recognized (i.e., Caribbean, Pacific, Andean, Orinoquia and Amazon), among which the Orinoquia is the second most diverse in mammals, only surpassed by the Andean (Pardo \& Rangel-Ch, 2014). The Orinoquia region is composed of several ecosystems, mainly savannas (known locally as "Llanos Orientales") which are distributed from the eastern side of the Andean mountain range to the Orinoco River north of the Guaviare river basin and total an area of around $230,000 \mathrm{~km}^{2}$ (Rippstein et al., 2001).

Within the Llanos Orientales, there are three main types of savannas: floodplain savannas, 
piedmont savannas, and high-plain savannas, (Rippstein et al., 2001). Floodplain savannas include several ecosystems such as aeolian savanna, gallery forest, and pastures (Romero-Ruiz et al., 2010) and are characterized by high productivity due to the accumulation of rainfall during eight months of the year (Mora-Fernandez et al., 2015; Sarmiento, 1983). By contrast, high-plain savannas have less productivity and complexity than floodplain savannas, due to the lower nutrient input from the Guyanese Shield (Sarmiento, 1983).

Despite the high biodiversity of the region, currently the Llanos Orientales is a strategic region for the national economy, according to government planning (DNP, expected to increase from 81,000 acres to 780,000 acres, and $\$ 9.6$ billion Colombian pesos ( $\$ 3.2$ million USD) has been designated for infrastructure projects such as road networks (CONPES, 2014).

Under this scenario, knowledge of mammal diversity, distribution and ecology is important for decision-making, in order to implement sustainable land use in the Orinoquia Region, especially, when there is still a large gap in basic information about the mammals of the Colombian Llanos (Ferrer-Pérez et al., 2009). Despite some studies about mammal responses to oil palm dominated landscapes (Pardo et al., 2018a, b; Pardo \& Payán, 2015), regional checklists (Ferrer-Pérez et al., 2009), and technical reports of conservation planning (Borón \& Payán, 2013; Díaz-Pulido \& Payán, 2009), knowledge of mammal assemblages and their attributes (such as relative abundances and trophic composition) in different savanna ecosystems is almost nonexistent for this region. Comparing the structure of mammal assemblages across the savannas of the Colombian Llanos is an im2016). For instance, the productive land for agriculture is

portant step toward understanding the distribution and functional contribution of mammal communities in each of these ecosystems and on a regional scale.

In this context, we aimed to compare the composition and structure of assemblages of medium and large mammals in terms of species richness, relative abundance, and the species contributions to trophic guilds at three different ecosystems along the Colombian Llanos: floodplain savannas associated with an Andean river, aeolian savannas and highland savannas associated to the Guyanese Shield. We discuss the value of savanna ecosystems as areas of special importance for the conservation of medium- and large-sized mammals in the Colombian Llanos.

\section{MATERIALS AND METHODS}

\section{Study area}

The study comprised three savanna ecosystems in the departments of Arauca, Casanare and Vichada, located in the Orinoquia region (Fig. 1A-C). The regional climate has a unimodal rainfall pattern with a wet season (from April to November) and a short dry period (December to March). Savannas' vegetal communities vary in relation to flood level and topography (Mora-Fernandez et al., 2011). The three ecosystems are described below:

\section{Ecosystem 1: Floodplain savannas, Arauca (SE-1)}

Mosaic of floodplain savannas (74\%), riparian stratified forest (16,6\%) and exotic pastures (9,4\%). The forest of
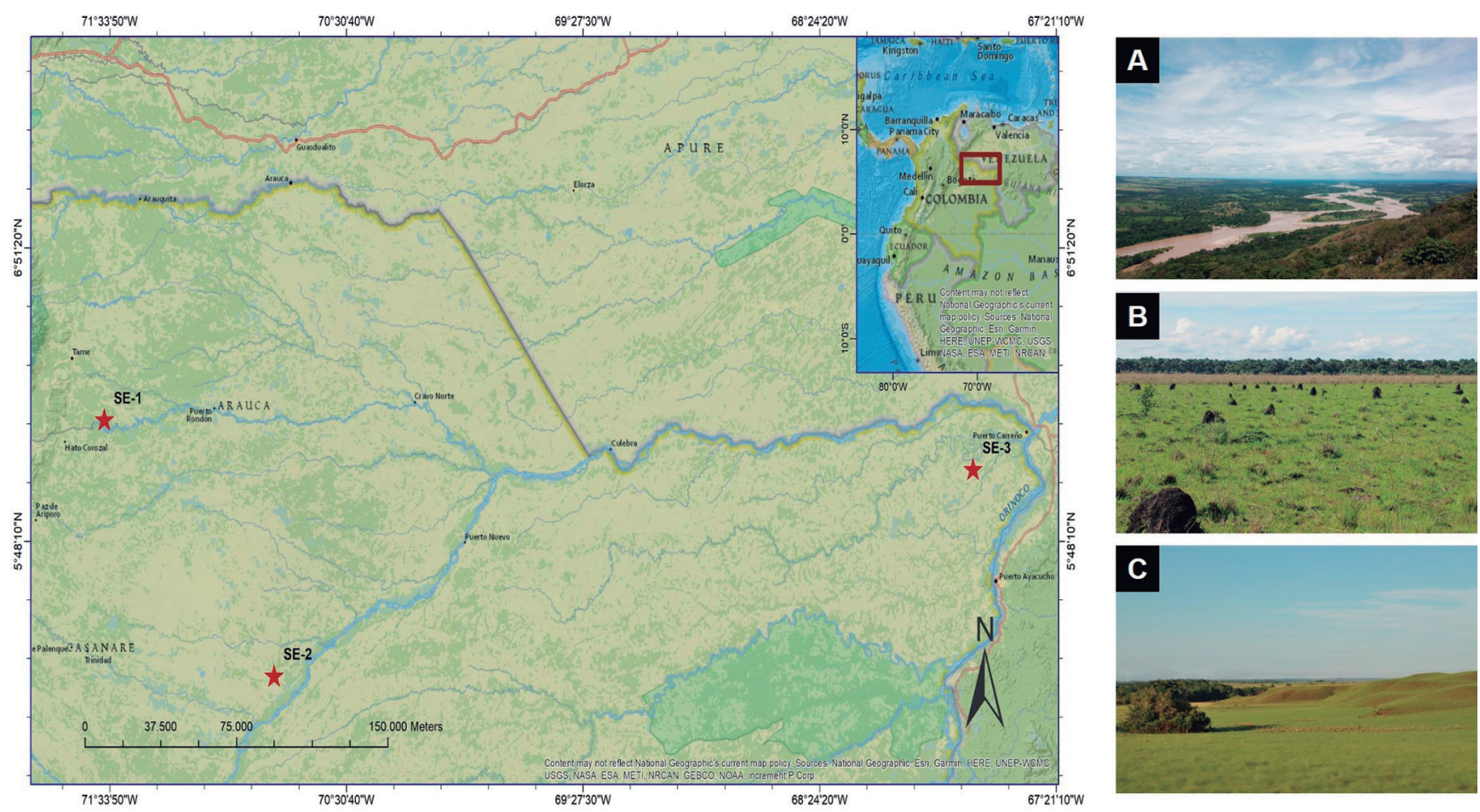

Figure 1. Geographical location of the localities studied in the three savanna ecosystems sampled in the Colombian Llanos: (A) SE-1., floodplain savannas (Arauca); (B) SE-2., aeolian savannas (Casanare); (C) SE-3., high-plain savannas (Vichada). 
this ecosystem is a dense high forest that grows on floodplains bordering whitewater Andean rivers (Casanare River) that deposit on the soil a lot of nutrients (Baptiste \& Ariza, 2008; Etter, 1998). The plant community of these forests is characterized by higher density of trees (> 70\%), with a diameter at breast height (dbh) larger than $1 \mathrm{~m}$ and heights ranging from 6 to more than $25 \mathrm{~m}$ and constitute a more or less continuous canopy stratum (MoraFernandez et al., 2011; Romero et al., 2004). This study site was placed in the department of Arauca, municipality of Tame, in the villages of San Salvador and San Joaquin, within the Casanare river basin $\left(6.2398^{\circ},-71.5863,172 \mathrm{~m}\right.$; Fig. 1A). It is currently facing landscape transformation processes due to several anthropogenic activities such as oil and gas industry. Also these forests contain a higher percentage of nutrients (Baptiste \& Ariza, 2008) and therefore, farmers use floodplain rivers to grow different crops due to the high fertility of its soils, consequently these forests are partially fragmented (30\%).

\section{Ecosystem 2: Aeolian savannas, Casanare (SE-2)}

Mosaic of aeolian floodplain savannas $(71,1 \%)$, floodplain forests $(14,2 \%)$, grasslands $(0,6 \%)$, exotic pastures $(9,8 \%)$ and crops $(4,3)$. These forests develop in the banks of rivers, streams and creeks that are born in the savannas, in contrast with riparian stratified forests, their trees have smaller size, with a diameter at breast height ( $\mathrm{dbh}$ ) of no more than $50 \mathrm{~cm}$ and a canopy height of $20 \mathrm{~m}$ (Mora-Fernandez et al., 2011). This second study site was set up in the department of Casanare, municipality of Trinidad, in the villages of San Cristóbal and Santa Marta, which are located inside the privately protected area of Altragracia-Trinidad $\left(5.3204^{\circ},-70.8310,119\right.$ m; Fig. 1B). This ecosystem has been transformed by agricultural and mining activities such as livestock raising, hydrocarbon projects, some crops of rice and improved pastures.

\section{Ecosystem 3: High-plain savannas, Vichada (SE-3)}

Mosaic of high-plain savannas (77\%), floodplain forests $(16,1 \%)$ and timber species crops (4,8\%). These forests are fed by the Bita river, which is a mixed-water river born in the savanna. The vegetation is defined by a density of trees with a diameter at breast height $(\mathrm{dbh})$ of $50 \mathrm{~cm}$, with heights ranging from 5 to $20 \mathrm{~m}$ (Mora-Fernandez et al., 2015). The third sampling site was in the department of Vichada, municipality of Puerto Carreño, on the premises of La Pedregoza farm, which is situated inside of the privately protected area of the Pedregoza, within the Bita river basin $\left(6.0618^{\circ},-67.7222,72\right.$ m; Fig. 1C). Anthropogenic activities include small-scale agricultural uses in livestock raising and farming crops such as rice and maize. In comparison to the other savanna ecosystems sampled (i.e., SE-1 and SE-2), this is the least disturbed by anthropogenic pressures. This is mainly because these forests do not have a value for agriculture, instead some of them are burned to expand pastures and savannas (Mora-Fernandez et al., 2011).

\section{Medium- and large-sized mammal sampling}

This study was carried out at the end of the wet season (October to November), in three different ecosystems (SE-1, SE-2 and SE-3), described above (Fig. 1). For each one of them, 30 sites were sampled by placing 30 camera traps (Bushnell Trophy Cam) in the field for 35 consecutive days. A minimal distance of $1.1 \mathrm{~km}$ between traps was used (O'Brien et al., 2003). The camera traps were in both forest, crops, exotic pastures and savannas. Cameras were set at an average height of $40 \mathrm{~cm}$ above ground to be able to capture medium-and large-sized mammals and programmed to take three pictures per trigger with intervals of one second between pictures. Cameras ran $24 \mathrm{~h}$ per day recording date and time of each photograph. We did not use any kind of bait to attract mammals.

\section{Data analyses}

The taxonomic treatment of the species detected was based on Ramírez-Chaves et al., 2016 and Solari et al., 2013. To analyze the images from the camera traps we used the software NAIRA III (Pulido-Castelblanco et al., 2017). To estimate species accumulation curves and the total species richness we used Estimates 9.0 (Colwell, 2013). In doing so, we took the number of days in which the cameras were activated, and the number of species observed to plot the accumulation curves. We used the richness estimator of Chao 2 after randomizing the samples 1,000 times. The use of Chao 2 is because of two reasons: firstly, this non-parametric estimator of species richness avoids problems related to detection probabilities and abundance estimation using incidence data (Pardo et al., 2018a); secondly, Chao 2 provides the least biased estimates for small numbers of samples (Colwell \& Coddington, 1994), as in this study.

To test differences in relative abundance of species and trophic guilds among the three mammal assemblages, analysis of similarity (ANOSIM) was applied to two different matrices: one for estimating relative abundances of each species and the other to estimate the contribution of those species in the different trophic guilds. This non-parametric permutation test is frequently used to examine the difference between two or more groups of sampling units (Clarke, 1993). ANOSIM produces values of $\mathrm{R}$ between -1 (total similarity) and +1 (total dissimilarity) (Clarke, 1993). The probability values were estimated based on 9,999 permutations.

As a surrogate of relative abundance, the capture rate was estimated as the number of independent events relative to the sampling effort, scaled to 100 trap/days (Pardo \& Payán, 2015). Photographs taken of the same species in the same place were considered independent if separated by at least an hour (Cruz et al., 2014), thus avoiding pseudoreplication (O'Brien et al., 2003). Finally, we assigned general trophic guilds (i.e., herbivorous, insectivorous, carnivorous and omnivorous) based on literature (Mosquera-Guerra et al., 2018; Muñoz-Saba 
et al., 2016; Jones et al., 2009) and the conservation status National (Rodríguez-Mahecha et al., 2006) and International (IUCN, 2019) of each species recorded.

The contribution of each mammal species to dissimilarity among assemblages was evaluated using SIMPER percentage analysis (Clarke, 1993). To compare species richness and number of events of medium- and largesized mammals between the three ecosystems, KruskalWallis test were applied. All these statistical analyses were carried out in PAST 3.0 (Hammer et al., 2001) and RWizard 3.0 (Guisande et al., 2014).

\section{RESULTS}

\section{Species richness and relative abundance}

We recorded 16 mammal species distributed in 6 orders, 12 families and 15 genera in the three savanna ecosystems (Table 1; Fig. 2A-I). The sampling representativeness for each ecosystem was above $80 \%$ based on Chao 2 estimator. The floodplain savannas (SE-1) presented the highest richness observed (14 spp. observed), which yielded a representativeness of $90.38 \%$ (Chao 2 mean $\pm S D=15.49 \pm 0.52$ ). This was followed by the aeo- lian savannas (SE-2 = 12 spp. observed) with a representativeness of $97.32 \%$ (Chao 2 mean \pm SD $=12.33 \pm 0.16$ ) and finally the high-plains savannas (SE-3 = 9 spp. observed) with a representativeness of $83.17 \%$ (Chao 2 mean \pm SD $=10.82 \pm 0.63$ ) (Fig. 3).

In general, five of the species were the most commonly recorded: Dasyprocta fuliginosa (17.9 trap/days), Pecari tajacu (14.48 trap/days), Odocoileus cariacou (8.57 trap/ days), Myrmecophaga tridactyla (7.15 trap/days), and Cuniculus paca (7.14 trap/days). Conversely, Puma yagouaroundi 0.29 trap/days), Sylvilagus sp. (0.38 trap/ days), Mazama gouazoubira (0.57 trap/days) and Puma concolor (0.59 trap/days) were the rarest mammalian species (Table 1). We did not record any endemic species. M. tridactyla was the only threatened species registered according to the local and global red lists.

\section{Structure of mammal assemblages}

Mammal assemblages differed significantly $(p<0.01)$ between all ecosystems according to ANOSIM analysis (Table 2). Based on SIMPER analysis, despite D. fuliginosa was dominant in both SE-1 and SE-2 (Table 3), its relative abundance was higher in SE-1 than SE-2 (Fig. 4).
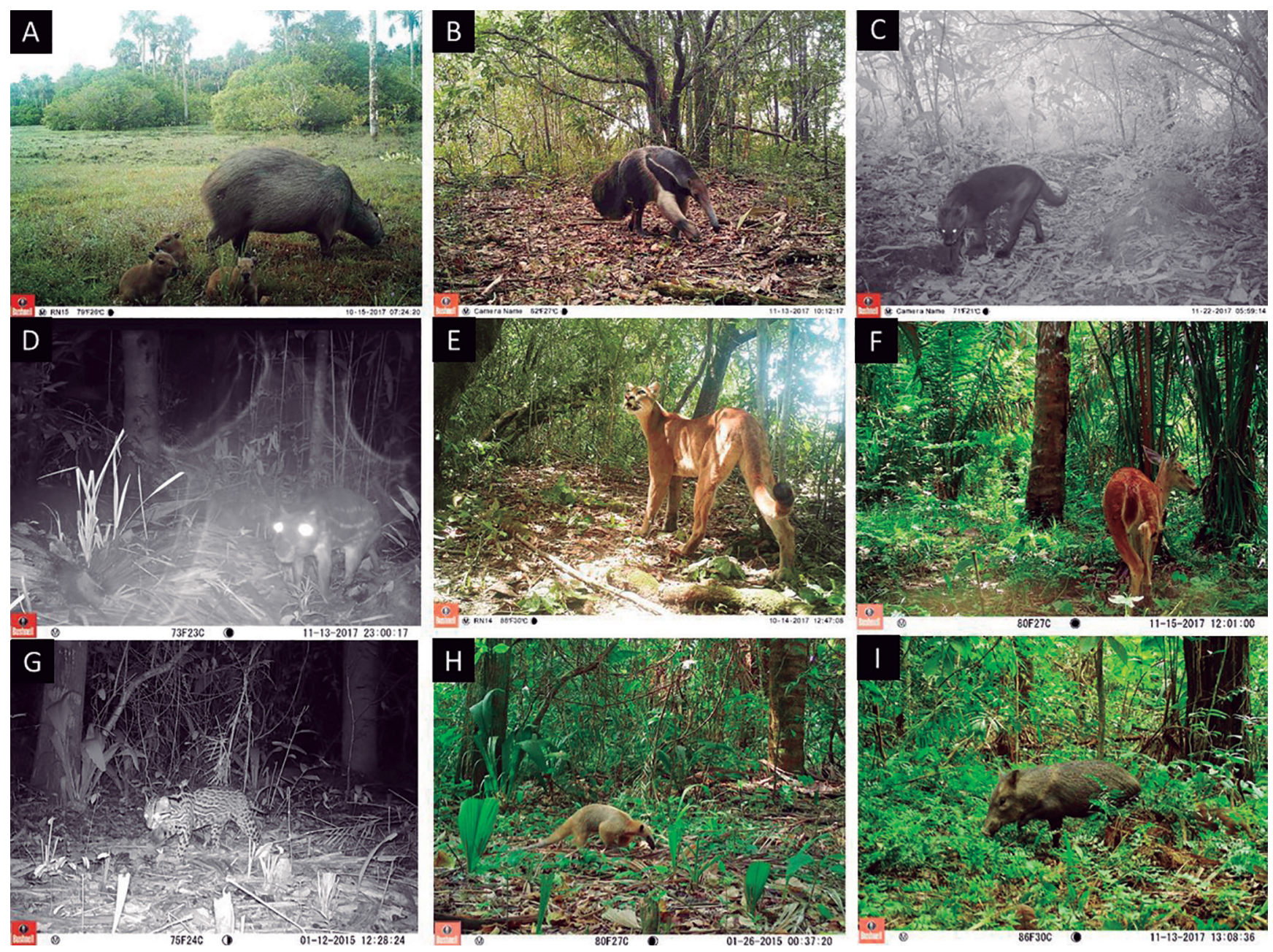

Figure 2. Some species recorded in Savanna ecosystems in the Colombian Llanos: (A) Hydrochoerus hydrochaeris; (B) Myrmecophaga tridactyla; (C) Puma yagouaroundi; (D) Cuniculus paca; (E) Puma concolor; (F) Odocoileus cariacou; (G) Leopardus pardalis; (H) Tamandua tetradactyla; (I) Pecari tajacu. 
Table 1. Medium- and large-sized mammals recorded in the three assemblages of the Colombian Llanos. International (A) and National (B) conservation status. IUCN Red List Categories: LC: Least Concern, VU:Vulnerable. CITES categories: Appendix I, II, III. NL: not listed. Total number of events in the three savanna ecosystems (SE-1, SE-2, SE-3).

\begin{tabular}{|c|c|c|c|c|c|c|c|c|}
\hline Taxa & Acronym & Trophic guilds & A & B & CITES 2017 & SE-1 & SE-2 & SE-3 \\
\hline \multicolumn{9}{|l|}{ DIDELPHIOMORPHIA } \\
\hline \multicolumn{9}{|l|}{ Didelphidae } \\
\hline Didelphis marsupialis & $\mathrm{Dm}$ & Omnivore & LC & LC & NL & 18 & 28 & 0 \\
\hline \multicolumn{9}{|l|}{ CINGULATA } \\
\hline \multicolumn{9}{|l|}{ Dasypodidae } \\
\hline Dasypus novemcinctus & Dv & Omnivore & LC & LC & NL & 22 & 6 & 0 \\
\hline \multicolumn{9}{|l|}{ PILOSA } \\
\hline \multicolumn{9}{|l|}{ Myrmecophagidae } \\
\hline Tamandua tetradactyla & Tt & Insectivore & $\mathrm{LC}$ & LC & $\mathrm{NL}$ & 29 & 20 & 1 \\
\hline Myrmecophaga tridactyla & Mt & Insectivore & VU & VU & $\|$ & 45 & 28 & 2 \\
\hline \multicolumn{9}{|l|}{ RODENTIA } \\
\hline \multicolumn{9}{|l|}{ Caviidae } \\
\hline Hydrochoerus hydrochaeris & $\mathrm{Hh}$ & Herbivore & LC & LC & NL & 1 & 26 & 0 \\
\hline \multicolumn{9}{|l|}{ Cuniculidae } \\
\hline Cuniculus paca & $\mathrm{Cc}$ & Herbivore & $\mathrm{LC}$ & LC & III & 48 & 25 & 2 \\
\hline \multicolumn{9}{|l|}{ Dasyproctidae } \\
\hline Dasyprocta fuliginosa & Df & Herbivore & LC & LC & $\mathrm{NL}$ & 132 & 54 & 2 \\
\hline \multicolumn{9}{|l|}{ Canidae } \\
\hline Cerdocyon thous & $\mathrm{Ct}$ & Omnivore & $\mathrm{LC}$ & $\mathrm{LC}$ & $\|$ & 10 & 3 & 8 \\
\hline \multicolumn{9}{|l|}{ Felidae } \\
\hline Puma concolor & Pc & Carnivore & $\mathrm{LC}$ & NT & I & 0 & 5 & 1 \\
\hline Puma yagouaroundi & Py & Omnivore & $\mathrm{LC}$ & LC & ॥ & 3 & 0 & 0 \\
\hline Leopardus pardalis & $L p$ & Carnivore & $\mathrm{LC}$ & NT & I & 13 & 6 & 0 \\
\hline \multicolumn{9}{|l|}{ Mustelidae } \\
\hline Eira barbara & $E b$ & Omnivore & LC & LC & III & 14 & 0 & 0 \\
\hline \multicolumn{9}{|l|}{ CETARTIODACTYLA } \\
\hline \multicolumn{9}{|l|}{ Cervidae } \\
\hline Mazama gouazoubira & $\mathrm{Mg}$ & Herbivore & LC & LC & $\mathrm{NL}$ & 6 & 0 & 0 \\
\hline Odocoileus cariacou & $0 c$ & Herbivore & $\mathrm{LC}$ & LC & III & 36 & 50 & 4 \\
\hline \multicolumn{9}{|l|}{ Tayassuidae } \\
\hline Pecaritajacu & Pt & Herbivore & LC & LC & $\|$ & 139 & 7 & 6 \\
\hline \multicolumn{9}{|l|}{ LAGOMORPHA } \\
\hline \multicolumn{9}{|l|}{ Leporidae } \\
\hline Sylvilagus sp. & $S$ & Herbivore & 一 & 一 & $\mathrm{NL}$ & 0 & 0 & 4 \\
\hline Total & & & & & & 516 & 260 & 30 \\
\hline
\end{tabular}

Table 2. ANOSIM on species composition and trophic guilds of medium- and large-mammals in the three assemblages of the Colombian Llanos using a dissimilarity matrix based on Bray-Curtis similarity index.

\begin{tabular}{lcccc}
\hline & \multicolumn{2}{c}{ Species } & \multicolumn{2}{c}{ Trophic guilds } \\
\cline { 2 - 5 } & $\mathbf{R}$ & $\boldsymbol{p}$ & $\mathbf{R}$ & $\boldsymbol{p}$ \\
\hline Between all sites & 0.34 & $<0.01$ & 0.39 & $<0.01$ \\
SE-1 and SE-2 & 0.23 & $<0.01$ & 0.09 & $<0.01$ \\
SE-1 and SE-3 & 0.47 & $<0.01$ & 0.58 & $<0.01$ \\
SE-2 and SE-3 & 0.35 & $<0.01$ & 0.47 & $<0.01$ \\
\hline
\end{tabular}

Additionally, P. tajacu was the commonest species in SE-1 but was rare in SE-2 (Fig. 4). Regarding SE-1 vs SE-3, the dominance of $D$. fuliginosa in SE-1 and the absence of many species in SE-3 such as Eira barbara, P. yagouaroundi, Didelphis marsupialis, and M. gouazoubira shows important differences among these two ecosystems (Table 4). In SE-2 vs SE-3, O. cariacou had the highest con-

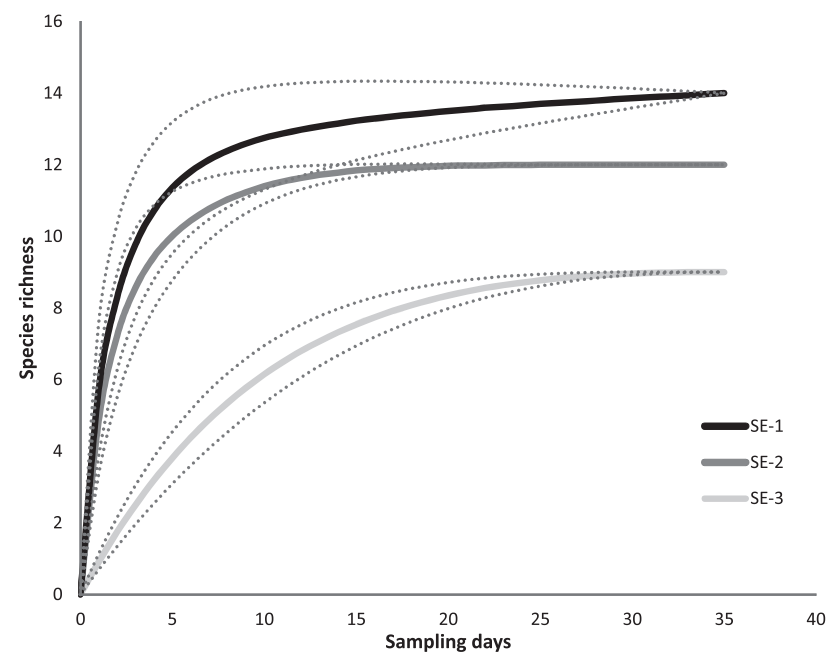

Figure 3. Species accumulation curves at the three savanna ecosystems of Colombian Llanos. Dotted lines show 95\% confidence interval. 


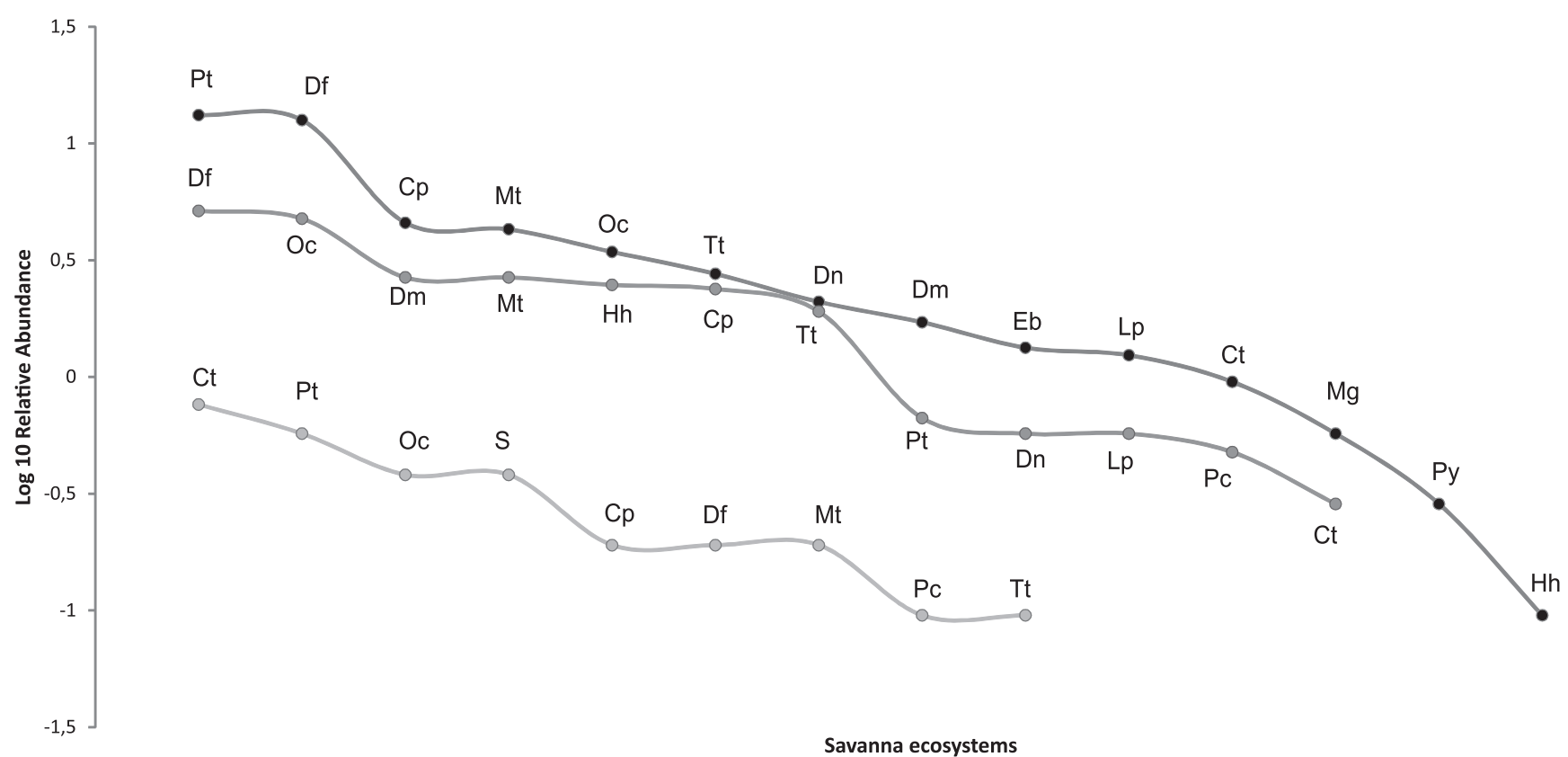

$\bullet$ SE-1 $\longrightarrow$-SE-2 $\multimap-\mathrm{SE}-3$

Figure 4. Rank-abundance curves of medium- and large-sized mammals recorded at the three savanna ecosystems of the Colombian Llanos. Species acronyms are listed in Table 1.

Table 3. Contribution of each species and trophic guild to the dissimilarity among SE-1 and SE-2. Abbreviations: Avg SE-1., average of abundance in SE-1; Avg SE-2., average of abundance in SE-2; Avg. dissimilarity, average contribution to the total dissimilarity; \% ac., accumulative percentage contribution to dissimilarity. ${ }^{\left({ }^{a}\right)}$ Overall average dissimilarity: $71.36 .{ }^{(b)}$ Overall average dissimilarity: 48.17 .

\begin{tabular}{lcccc}
\hline \multicolumn{1}{c}{ SE-1 and SE-2 } & Avg. SE-1 & Avg. SE-2 & Avg. dissimilarity & \% ac. \\
\hline Species $^{\mathbf{a}}$ & & & & \\
Dasyprocta fuliginosa & 3.77 & 1.54 & 14.81 & 20.77 \\
Pecari tajacu & 3.97 & 0.2 & 10.92 & 36.08 \\
Odocoileus cariacou & 1.03 & 1.43 & 8.50 & 48.01 \\
Cuniculus paca & 1.37 & 0.71 & 7.08 & 57.95 \\
Myrmecophaga tridactyla & 1.29 & 0.80 & 6.06 & 66.45 \\
Didelphis marsupialis & 0.51 & 0.80 & 4.67 & 73.03 \\
\hline Trophic guilds & & & & \\
Herbivore & 10.3 & 4.60 & 28.74 & 59.14 \\
Insectivore & 2.11 & 1.29 & 8.79 & 77.23 \\
Omnivore & 1.86 & 1.09 & 7.79 & 93.26 \\
Carnivore & 0.51 & 0.31 & 3.26 & 100 \\
\hline
\end{tabular}

tribution to the dissimilarity due to its high abundance in SE-2 and scarcity in SE-3 (Fig. 4). Furthermore, the presence of Sylvilagus sp. only in SE-3 shows also differences between these two assemblages (Table 5).

Statistical differences were also found in species richness $(\mathrm{H}=63.59 ; \mathrm{DF}=2 ; p<0.05)$ and number of events $(\mathrm{H}=70.28 ; \mathrm{DF}=2 ; p<0.05)$ among ecosystems in all the one-way Kruskal-Wallis comparisons (Fig. 5).

\section{Trophic guilds}

Our results showed significant differences $(p<0.01)$ among the assemblages in terms of the contribution of
Table 4. Contribution of each species and trophic guild to the dissimilarity among SE-1 and SE-3. Abbreviations: Avg SE-1., average of abundance in SE-1; Avg SE-3., average of abundance in SE-3; Avg. dissimilarity, average contribution to the total dissimilarity; \% ac., accumulative percentage contribution to dissimilarity. ${ }^{\left({ }^{a}\right)}$ Overall average dissimilarity: $95.89 .{ }^{(b)}$ Overall average dissimilarity: 87.86 .

\begin{tabular}{lcccc}
\hline \multicolumn{1}{c}{ SE-1 and SE-3 } & Avg. SE-1 & Avg. SE-3 & Avg. dissimilarity & \% ac. \\
\hline Species $^{\mathrm{a}}$ & & & & \\
Dasyprocta fuliginosa & 3.77 & 0.05 & 27.18 & 28.34 \\
Pecari tajacu & 3.97 & 0.17 & 14.08 & 43.02 \\
Cuniculus paca & 1.37 & 0.05 & 12.54 & 56.09 \\
Myrmecophaga tridactyla & 1.29 & 0.05 & 9.43 & 65.94 \\
Tamandua tetradactyla & 0.82 & 0.02 & 5.67 & 71.86 \\
Odocoileus cariacou & 1.03 & 0.11 & 5.59 & 77.69 \\
\hline Trophic guilds $^{\mathrm{b}}$ & & & & \\
Herbivore & 10.3 & 0.51 & 55.69 & 63.39 \\
Insectivore & 2.11 & 0.11 & 14.85 & 80.29 \\
Omnivore & 1.86 & 0.25 & 13.57 & 95.74 \\
Carnivore & 0.51 & 0 & 3.74 & 100 \\
\hline
\end{tabular}

each trophic guild (Table 2; Fig. 6). In all three study sites herbivores had the highest abundance, followed by insectivores and omnivores. Dissimilarity was determined by the strongest contribution of herbivores in all the comparisons (> 59\%) (Tables 3-5). By contrast, the carnivore's guild had the lowest abundances in all the ecosystems (Fig. 6).

\section{DISCUSSION}

We found 16 medium and large-sized mammal species in the three savanna ecosystems sampled, which represent $9,46 \%$ of Orinoco river basin mammals (Ferrer- 

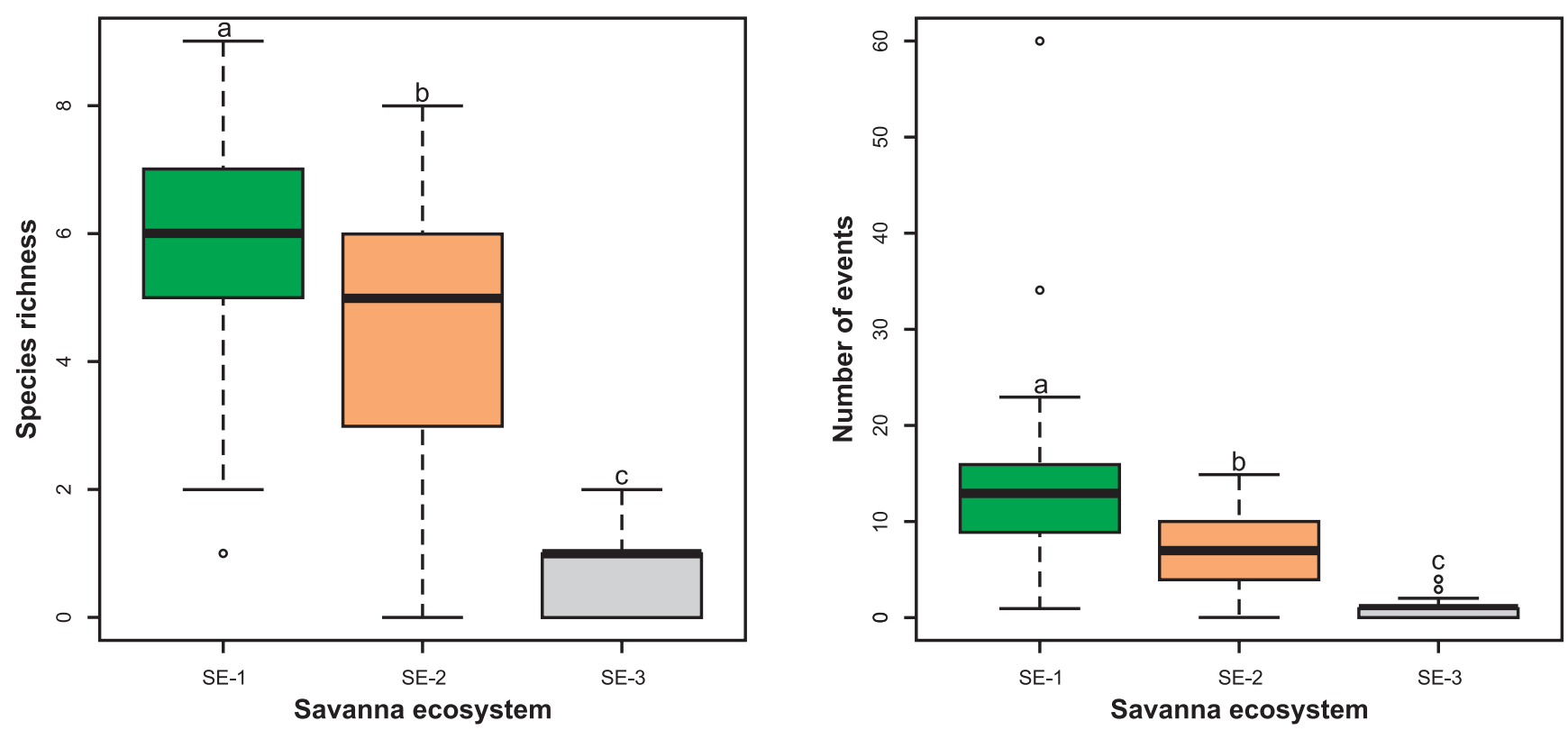

Figure 5. Comparisons of mean species richness and total number of events of medium- and large-sized mammals among the three savanna ecosystems of the Colombian Llanos. Boxplots with different letters denotes significant differences among means $(p<0.05)$.

Table 5. Contribution of each species and trophic guild to the dissimilarity among SE-2 and SE-3. Abbreviations: Avg SE-2., average of abundance in SE-2; Avg SE-3., average of abundance in SE-3; Avg. dissimilarity, average contribution to the total dissimilarity; \% ac., accumulative percentage contribution to dissimilarity. ${ }^{\left({ }^{a}\right)}$ Overall average dissimilarity: $92.4 .{ }^{\left({ }^{b}\right)}$ Overall average dissimilarity: 82.4 .

\begin{tabular}{|c|c|c|c|c|}
\hline SE-2 and SE-3 & Avg. SE-2 & Avg. SE-3 & Avg. dissimilarity & $\%$ ac. \\
\hline \multicolumn{5}{|l|}{ Species $^{\mathrm{a}}$} \\
\hline Odocoileus cariacou & 1.43 & 0.11 & 17.90 & 19.39 \\
\hline Dasyprocta fuliginosa & 1.54 & 0.05 & 16.63 & 37.40 \\
\hline Didelphis marsupialis & 0.8 & 0 & 9.94 & 48.17 \\
\hline Myrmecophaga tridactyla & 0.8 & 0.05 & 9.31 & 57.77 \\
\hline Hydrochoerus hydrochaeris & 0.74 & 0 & 7.72 & 66.96 \\
\hline Cuniculus paca & 0.71 & 0.05 & 6.99 & 74.54 \\
\hline \multicolumn{5}{|l|}{ Trophic guilds $^{b}$} \\
\hline Herbivore & 4.60 & 0.51 & 48.57 & 59.01 \\
\hline Insectivore & 1.29 & 0.11 & 14.86 & 77.07 \\
\hline Omnivore & 1.09 & 0.25 & 14.74 & 94.97 \\
\hline Carnivore & 0.31 & 0 & 4.14 & 100 \\
\hline
\end{tabular}

Pérez et al., 2009) and 5,06\% of Colombian mammals (Ramírez-Chaves et al., 2016). Camera trapping method showed its effectiveness in the record of elusive carnivores with low population densities such as $P$. concolor, L. pardalis and $P$. yagouarundi, species which are under threat due to activities such as hunting, habitat transformation and death by retaliation (Mosquera-Guerra et al., 2018). Despite our sampling effort reached more than the $80 \%$ (83\%-97\%) of mammal species in the three ecosystems (Fig. 3), other surveys conducted in these study sites have reported a higher richness than this study. For instance, Pardo \& Payán (2015) recorded 16 species in Orocué River (Casanare) and Mosquera-Guerra et al. (2018) reported 24 species along the upper and mid basin of the Bita River (Vichada), which is higher than the richness presented here (14 and 9 species, respectively).

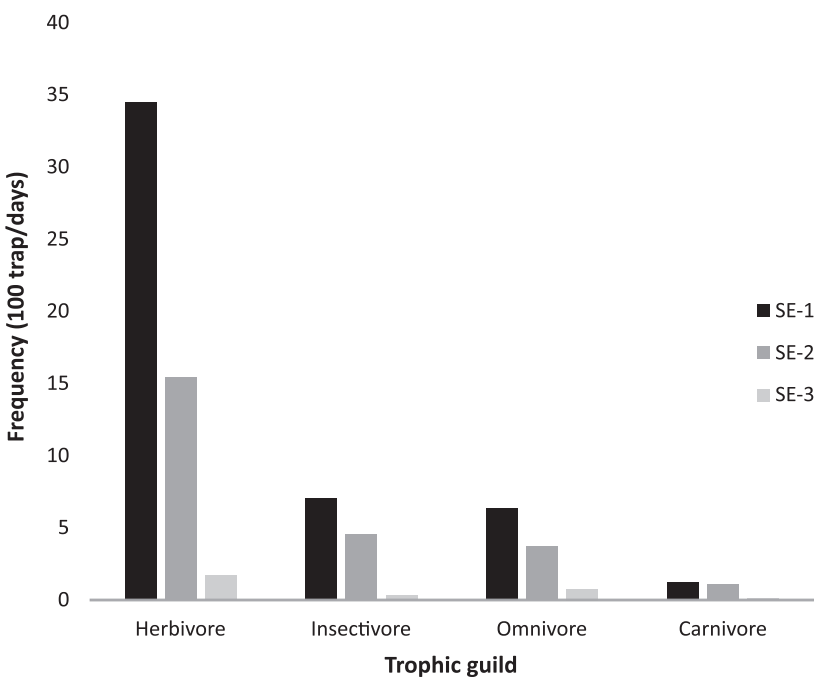

Figure 6. Frequency of tropic guilds recorded at the three savanna ecosystems of the Colombian Llanos.

Assemblages of medium and large mammals from the three different savanna ecosystems were different in their structure, composition, and trophic guilds (Table 2; Figs. 4 and 6). This may result from the high variability of habitat characteristics among the different savanna types. At a local scale, the savanna ecosystems located in the Colombian Llanos have different floristic compositions (Trujillo \& Henáo-Cárdenas, 2018). Different vegetative cover and habitat complexity in each of the savanna ecosystems, may provide different resources to particular mammalian species groups (Dotta \& Verdade, 2007; Gallina et al., 1996). As August (1983) has pointed out, the structure of Neotropical mammals could be influenced by habitat physiognomy and horizontal variation in vegetation forms, due to the availability of myriad ecological niches for mammals. Indeed, recent studies conducted in an Atlantic rain-forest reserve of Brazil have demon- 
strated differences in mammal composition in different vegetation types (Ferreguetti et al., 2017). Even though there is a lack of this kind information for medium- and large-sized mammals in savanna ecosystems, for other mammal taxa, such as bats, some investigations suggest the high heterogeneity of savanna ecosystems as one of the main explanations of the high species turnover between assemblages at a regional scale (Morales-Martínez et al., 2018).

In our study, floodplain savannas (SE-1) presented the highest richness and capture rates, followed by aeolian savannas (SE-2) (Figs. 4 and 5), probably due to hydrological dynamics and the high quantity of nutrients which flow from Andean sediments (Mora-Fernandez et al., 2015; Rippstein et al., 2001). This has an important effect on plant diversity and therefore vertical and horizontal stratification, resulting in heterogeneous, complex and multistratified forest. Consequently, this variety of vegetation types could provide greater resource availability for mammals, resulting in higher species diversity in comparison with simpler and less productive environments (Ferreguetti et al., 2017). Therefore, the sediment fluxes of the high-plains (SE-3) originate from the Guyanese Shield, result in lower nutrient availability for this ecosystem (Sarmiento, 1983), which is probably reflected in the low mammal diversity. Despite the low anthropogenic transformation of this ecosystem, we found few mammal species, which indicates its vulnerability and makes it a target ecosystem for conservation. However, in SE-3 we did not record other mammals reported for Vichada department such as Tapirus terrestris, Pteronura brasiliensis and Lontra longicaudis (MosqueraGuerra et al., 2018; Mosquera-Guerra et al., 2017), perhaps because of differences in the sampling design as well as the seasons and vegetation covers that were sampled in each study.

In terms of the trophic guilds, differences related to ecological function were detected among the three mammal assemblages, although in all cases the herbivores were the most important guild (Fig. 6). Herbivores have a remarkable role in the carbon cycle due to the translocation of organic matter from plants through feeding and subsequent defecation and death. This contributes to soil carbon storage, which increases plant diversity and productivity (Sobral et al., 2017). Furthermore, herbivores such as $D$. fuliginosa, C. paca perform unique ecological roles in the dispersal of large seeds (Acevedo-Quintero \& Zamora-Abrego, 2016), which are primarily restricted to large body-sized dispersers (Bello et al., 2015). This highlights the importance of herbivores to these ecosystems given the large seed diameter of Neotropical palm species (Andreazzi et al., 2009), many of which are present in savanna ecosystems of the Colombian Llanos.

Insectivores were the second most important guild (Fig. 6). Within this group, despite M. tridactyla was one of the most common species (Fig. 4), also was the only species categorized as Vulnerable by red list of threatened species at national (Rodríguez-Mahecha et al., 2006) and international scale (Miranda et al., 2014). In the case of T. tetradactyla, although considerable threats such as dog attacks, habitat loss and vehicle collisions can compromise its conservation status (Miranda et al., 2014), this species was detected in all three savanna ecosystems (Fig. 4). Some studies report that these species can utilize different habitats across the Llanos region such as plantations of Acacia mangium, Eucalyptus sp. (Rojano et al., 2015b), oil palm (Elaeis guinensis) (Pardo et al., 2018a; Pardo \& Payán, 2015) and rice crops (Oryza sativa), among others (Rojano et al., 2015a). Our findings agree with this idea, considering that the three savanna ecosystems were under anthropogenic pressures such as livestock ranching, oil and palm industry, and farming crops (see Materials and Methods). Accordingly, insectivores may persist in different ecosystems, even when those are immersed in highly transformed landscapes, and despite their specific diet (Pardo et al., 2018a). Nonetheless, this guild needs coverage of gallery and riparian forest, due to their dependency on this kind of habitats for thermoregulation (Camilo-Alves \& Mourão, 2006), resting (Mourão \& Medri, 2007), and finding food resources in the arboreal insect nests (Montgomery \& Lubin, 1977). Mammalian terrestrial insectivores have a key role in topdown effects on their prey on the ground as well on trees and lianas (e.g., termites, ants, bees) (Gallo et al., 2017; Hirsch et al., 2014). Therefore, conservation of this guild is important to regulate trophic interactions in savanna ecosystems.

Omnivore abundance and species composition differed between ecosystems (Fig. 6). The reduced species richness in the less disturbed ecosystem (SE-3) could be the response of omnivores to resource availability. Some types of human-induced changes (e.g., livestock systems, crops, human constructions) can bring shelter and food resources that omnivorous mammals take advantage of (Gehring \& Swihart, 2003). Additionally, omnivores increase their prey intake rate due to the high prey density harbored in the habitat mosaic of agricultural landscapes (Pardo \& Payán, 2015; Oehler \& Litvaitis, 1996), such as in SE-1 and SE-2 (Fig. 4).

Carnivores were the least recorded trophic guild (Tables 4-6). It is known that these organisms have large home ranges (Suárez-Castro \& Ramírez-Chaves, 2015) in which they display a variety of behaviors such as foraging, feeding, territory and reproduction (Gittleman \& Harvey, 1982). On the other hand, local extinctions of top predators, such as Panthera onca and $P$. concolor, probably generate trophic cascades (Estes et al., 2011; Crooks \& Soulé, 1999); Hence, the conservation of high-quality habitats like gallery forest is important to maintain populations of these top predators (Johnson et al., 1999; Redford \& Fonseca, 1986). In our study, P. onca was not recorded in any of the three savanna ecosystems, although its presence has been reported for the Colombian Llanos (Ferrer-Pérez et al., 2009).

It is important to mention that in our study we only sampled three savanna ecosystems, while in the Llanos region we could find other types of savannas, including seasonal, semi-seasonal and hyper-seasonal savannas, and among them we can find from open savanna to tree savanna according to the average tree density and vege- 
tative species present (Correa et al., 2006; Rippstein et al., 2001; Sarmiento, 1983). From all these very different savanna types only one type (i.e., floodplain savanna) is represented at the conservation area of El Tuparro National Park (Correa et al., 2006). Recently, several additional areas of savanna have been recognized as important to include in protected areas as part of regional conservation planning. In this sense, the sampling stations of our study are included in the Civil Society Natural Reserves (RNSC). These areas are also recognized as important wildlife corridors known as the Meta-Casanare and Bita-MetaOrinoco corridors. These corridors maintain connectivity between protected areas and natural concentrations of biodiversity such as morichales, gallery forest and savanna ecosystems (Lasso et al., 2011). Our results show that the diversity of mammals is distributed heterogeneously in the Llanos Orientales, therefore, these private conservation initiatives are of high importance for the conservation of nuclear areas and the ecological connectivity between them (Romero-Ruiz et al., 2011).

Our work calls attention to the importance of including a variety of savanna types in the Colombian protected areas conservation network, given that each one of these ecosystems harbors a highly distinct mammal assemblage. The Llanos Orientales region lacks legislated protected areas, which would be useful to maintain populations of medium and large mammals. Another potential alternative is the contribution of privately-owned lands as actors of conservation at the local and regional scales (Pardo et al., 2018a), given the high mammal diversity and multiple anthropogenic activities developed in those sites.

In conclusion, mammal assemblages differed significantly across the three savanna ecosystems. Each mammal assemblage is an important unit of conservation, because of their highly distinctive variation in richness, species composition, relative abundances and trophic guilds. Accordingly, this information is key for decisions on current and future scenarios of anthropogenic transformation.

\section{ACKNOWLEDGMENTS}

We would like to thank primarily to the local people and landowners where the field phase of this study was carried out. To the owners of La Pedregoza in Puerto Carreño (Vichada), the local community of Puerto San Salvador (Arauca) and the San Cristobal and Santa Marta civil society reserves in Altagracia (Casanare). The data reported here were obtained as part of the cooperation agreement No. 100-15-17-018 between the autonomous regional corporation of the Orinoquia CORPORINOQUIA and Fundación Reserva Natural La Palmita, Research Center, for the conservation plan of anteaters in the departments of Arauca, Casanare and Vichada. We thank to the researchers of the Fundación La Palmita: Diego Gutiérrez Sanabria, Darwin Morales-Martínez, Diana Burbano and the biologists Camilo Fernández Rodríguez and Bibiana Gómez Valencia for the field work phase and the sampling design. We thank the Fundación Reserva Natural La Palmita, Research Center for administrative, technical and logistical support. Finally, we thank Jackie Willis and Josh Nightingale for the comments to the early version of the manuscript, and Laura L. GarzónSalamanca for her help in the preparation of the map.

Authors' contribution statement: Dennis CastilloFigueroa: analyzed the data, contributed to the theoretical and conceptual framework, wrote the paper, prepared figures and tables, reviewed drafts of the paper. Daniela Martínez-Medina: wrote the paper, contributed to material and methods, prepared figures, reviewed drafts of the paper. Miguel E. Rodríguez-Posada: wrote the paper, contributed to the theoretical and conceptual framework, designed the mammal sampling and reviewed drafts of the paper. Sandra Bernal-Vergara: wrote the paper, reviewed drafts of the paper.

Conflict of interest: The authors declare no conflict of interests.

\section{REFERENCES}

Acevedo-Quintero, J.F. \& Zamora-Abrego, J.G. 2016. Papel de los mamíferos en los procesos de dispersión y depredación de semillas de Mauritia flexuosa (Arecaceae) en la Amazonía colombiana. Revista de Biología Tropical, 64(1): 5-15.

Andreazzi, C.S.; Pires, A.S. \& Fernandez, F.A. 2009. Mamíferos e palmeiras neotropicais: interações em paisagens fragmentadas. Oecologia Brasiliensis, 13(4): 554-574.

August, P. 1983. The role of habitat complexity and heterogeneity in structuring tropical mammal communities. Ecology, 64(6): 1495-1507.

Baptiste, I. \& Ariza, A. 2008. Ecología de las Sabanas inundables de Casanare. In: Baleta, A. \& Benítez, J. (Eds.). Congreso Internacional de Producción y Desarrollo Sostenible, Versión Sabanas inundables, ${ }^{\circ}$. Memorias. Arauca, Universidad Cooperativa de Colombia. p. 120-140.

Bello, C.; Galetti, M.; Pizo, M.A.; Magnago, L.F.S.; Rocha, M.F.; Lima, R.A.F.; Peres, C.A.; Ovaskainen, 0. \& Jordano, P. 2015. Defaunation affects carbon storage in tropical forests. Science Advance, 1(11): e1501105.

Borón, V. \& Payan, E. 2013. Abundancia de carnívoros en el agropaisaje de las plantaciones de palma de aceite del valle medio del río Magdalena, Colombia. In: Castaño-Uribe, C.; González-Maya, J.F.; Ange, C.; ZarrateCharry, D. \& Vela-Vargas, M. (Eds.). Plan de conservación de felinos del Caribe colombiano 2007 2012: los felinos y su papel en la planificación regional integral basada en especies clave. Santa Marta, Fundación Herencia Ambiental Caribe, ProCAT Colombia, The Sierra to Sea Institute. p. $165-176$.

Camilo-Alves, C.S.P. \& Mourão, G. 2006. Responses of a specialized insectivorous mammal (Myrmecophaga tridactyla) to variation in ambient temperature. Biotropica, 38: 52-56.

Carrillo, J.D.; Forasiepi, A.; Jaramillo, C. \& Sánchez-Villagra, M.R. 2015. Neotropical mammal diversity and the Great American Biotic Interchange: spatial and temporal variation in South America's fossil record. Frontiers in Genetics, 5: 1-11.

Carthew, S.M. \& Goldingay, R.L. 1997. Non-flying mammals as pollinators. Trends in Ecology and Evolution, 12(3): 104-108.

Clarke, K.R. 1993. Non-parametric multivariate analyses of changes in community structure. Australian Journal of Ecology, 18(1): 117-143. 
Colwell, R.K. 2013. EstimateS: Statistical estimation of species richness and shared species from samples, Version 9.1. Available at: http://viceroy.eeb. uconn.edu/estimates. Access in: 05/09/2018.

Colwell, R.K. \& Coddington, J. 1994. Estimating terrestrial biodiversity through extrapolation. Philosophical Transactions of the Royal Society of London. Series B. Biological Sciences Royal Society, 345(345): 101-118.

Consejo Nacional de Política Económicay Social (CONPES). 2014. CONPES3797 para el desarrollo integral de la Orinoquia. Available at: https://colaboracion.dnp. gov.co/CDT/Conpes/Econ\%C3\%B3micos/3797.pdf. Access in: 15/09/2018.

Correa, H.; Ruiz S. \& Arévalo, L. 2006. Plan de acción en biodiversidad de la cuenca del Orinoco-Colombia/2005-2015 - Propuesta técnica. Bogotá, WWF-Colombia.

Crooks, K.R. \& Soulé, M.E. 1999. Mesopredator release and avifaunal extinctions in a fragmented system. Nature, 400: 563-566.

Cruz, P.; Paviolo, A.; Bó, R.F.; Thompson, J.J. \& Di Bitetti, M.S. 2014. Daily activity patterns and habitat use of the lowland tapir (Tapirus terrestris) in the Atlantic Forest. Mammalian Biology, 79(6): 376-383.

Departamento Nacional de Planeación (DNP). 2016. Plan maestro de la Orinoquía. Available at: http://www.dnp.gov.co. Access in: 1 June 2018.

Díaz-Pulido, A. \& Payán, E. 2009. Riqueza y Abundancia relativa de vertebrados terrestres en una reserva privada de la Orinoquía colombiana. Bogotá, Fundación Panthera, Fundación Palmarito. 23p. (Documento Técnico).

Dotta, G. \& Verdade, L.M. 2007. Trophic guilds in a mammal assemblage: diversity in an agricultural landscape. Biota Neotropical, 7(2): 287-292.

Estes, J.A.; Terborgh, J.; Brashares, J.S.; Power, M.E.; Berger, J.; Bond, W.J.; Carpenter, S.R.; Essington, T.E.; Holt, R.D.; Jackson, J.B.C.; Marquis, R.J.; Oksanen, L.; Oksanen, T.; Paine, R.T.; Pikitch, E.K.; Ripple, W.J.; Sandin, S.A.; Scheffer, M.; Schoener, T.W.; Shurin, J.B.; Sinclair, A.R.E.; Soulé, M.E.; Virtanen, R. \& Wardle, D.A. 2011. Trophic downgrading of planet Earth. Science, 333: 301-306.

Etter, A. 1998. Mapa general de ecosistemas de Colombia. In: Chaves, M.E. \& Arango, N. (Eds.). Informe Nacional sobre el estado de la biodiversidad en Colombia - 1997. Bogotá, Instituto Alexander Von Humboldt.

Ferreguetti, A.C.; Tomas, W.M., \& Bergallo, H.G. 2017. Differences in the mammalian habitat use in a mosaic of vegetation types of an Atlantic rain-forest reserve, Brazil. Mastozoología neotropical, 24(2): 355-364.

Ferrer-Pérez, A.; Beltrán, M.; Díaz-Pulido, A.; Trujillo, F.; Mantilla-Meluk, H.; Herrera, 0.; Alfonso, A. \& Payan, E. 2009. Lista de los mamíferos de la cuenca del río Orinoco. Biota Colombiana, 10(2): 179-207.

Gallina, S.; Mandujano, S. \& Gonzalez-Romero, A. 1996. Conservation of mammalian biodiversity in coffee plantations of Central Veracruz, México. Agroforestry Systems, 33(1): 13-27.

Gallo, A.; Abba, M.; Elizalde, L.; Cucci, D.; Ríos, T. \& Ezquiaga, M. 2017. First study on the food habits of anteaters, Myrmecophaga tridactyla and Tamandua tetradactyla, at the southern limit of their distribution. Mammalia, 81(6): 601-604.

Gehring, T.M. \& Swihart, R.K. 2003. Body size, niche breadth, and ecologically scaled responses to habitat fragmentation: mammalian predators in an agricultural landscape. Biological Conservation, 109(2): 283-295.

Giombini, M.I.; Bravo, S.P. \& Tosto, D.S. 2016. The key role of the largest extant Neotropical frugivore (Tapirus terrestris) in promoting admixture of plant genotypes across the landscape. Biotropica, 48(4): 499-508.

Gittleman, J.L. \& Harvey, P.H. 1982. Carnivore home range size, metabolic needs and ecology. Behavioral Ecology and Sociobiology, 10(1): 57-63.

Guisande, C.; Heine, J.; González-DaCosta, J. \& García-Roselló, E. 2014. RWizard Software. Available at: http://www.ipez.es/rwizard. Access in: $11 / 09 / 2018$.

Hammer, 0.; Harper, D. \& Ryan, P.D. 2001. PAST: Paleontological Statistics software package for education and data analysis. Palaentologia Electronica, 4(1): 1-9.
Hernández-Camacho, J.; Walschburger, T.; Ortiz, R. \& Hurtado, A. 1992. Origen y distribución de la biota suramericana y colombiana. In: Halffter, G. (Ed.). La Diversidad Biológica Iberoamericana I. Xalapa, Instituto de Ecologia. p. 55-104. (Acta zoológica Mexicana, volumen especial).

Hirsch, B.T.; Martinez, D.; Kurten, E.L.; Brown, D.D. \& Carson, W.P. 2014. Mammalian insectivores exert top-down effects on Azteca Ants. Biotropica, 46(4): 489-494.

International Union for Conservation of Nature and Natural Resources (IUCN). 2019. Available at de: http://www.iucnredlist.org. Access in: 18/01/2019.

Johnson, M.A.; Saraiva, P.M. \& Coelho, D. 1999. The role of gallery forests in the distribution of Cerrado mammals. Revista Brasileira de Biologia, 59(3): 421-427.

Jones, K.E.; Bielby, J.; Cardillo, M.; Fritz, S.A.; O'Dell, J.; Orme Safi, K.; Sechrest, W.; Boakes, E.H.; Carbone, C.; Connolly, C.; Cutts, M.J.; Foster, J.K.; Grenyer, R.; Habib, M.; Plaster, C.A.; Price, S.A.; Rigby, E.A.; Rist, J.; Teacher, A.; Bininda-Emonds, 0.R.P.; Gittleman, J.L.; Mace, G.M. \& Purvis, A. 2009. PanTHERIA: a species-level database of life history, ecology, and geography of extant and recently extinct mammals. Ecology, 90(9): 2648.

Lasso, C.; Rial, A.; Matallana, C.; Ramírez, W.; Selñaris, J.; Díaz-Pulido, A.; Corzo, G. \& Machado-Allison, A. 2011. Biodiversidad de la cuenca del Orinoco. II Áreas prioritarias para la conservación y uso sostenible, Instituto Alexander Von Humboldt, Bogotá.

Logiudice, K. \& Ostfeld, R.S. 2002. Interactions between mammals and trees: predation on mammal-dispersed seeds and the effect of ambient food. Oecologia, 130(3): 420-425.

Miranda, F.; Bertassoni, A. \& Abba, A. 2014. Myrmecophaga tridactyla. In: IUCN Red List Threat Species. Available at: http://www.iucnredlist.org/ details/14224/0. Access in: 27/06/2018.

Montgomery, G.G. \& Lubin, Y.D. 1977. Prey influences on movements of neotropical anteaters. In: Phillips, R.L \& Jonkel, C. (Eds.). Proceedings of the 1975 predator symposium. Montana forest and conservation experiment station. Missoula, University of Montana. p. 103-131.

Mora-Fernandez, C.; Castellano-Castro, C.; Cardona-Cardozo, C.; Pinzón-Pérez, L. \& Vargas-Ríos, 0. 2011. El medio natural: los Ilanos de Casanare y área de estudio. In: Ahumada, J.A. (Ed.). Mamíferos, reptiles y ecosistemas del Bloque Cubiro (Casanare): educación ambiental para la conservación. Bogotá, Instituto de Estudios Ambientales. p. 47-93.

Mora-Fernandez, C.; Peñuela-Recio, L. \& Castro-Lima, F. 2015. Estado del conocimiento de los ecosistemas de las sabanas inundables en la Orinoquia Colombiana. Orinoquia, 19(2): 253-271.

Morales-Martínez, D.; Rodríguez-Posada, M.; Fernandez-Rodríguez, C.; Calderón-Capote, M. \& Gutiérrez-Sanabria, D. 2018. Spatial variation of bat diversity between three floodplain-savanna ecosystems of the Colombian Llanos. Therya, 9(1): 41-52.

Mosquera-Guerra, F.; Trujillo, F.; Diaz-Pulido, A. \& Mantilla-Meluk, H. 2018. Diversidad, abundancia relativa y patrones de actividad de los mamíferos medianos y grandes, asociados a los bosques riparios del río Bita, Vichada, Colombia. Biota Colombiana, 19(1): 202-218.

Mosquera-Guerra, F.; Trujillo, F.; Mantilla-Meluk, H. \& Diaz-Pulido, A. 2017. Mamíferos. In: Trujillo, F. \& Lasso C.A. (Eds.). Biodiversidad del río Bita. Vichada, Colombia. Bogotá, Instituto Alexander Von Humboldt. p. 305-343. (Serie Editorial Fauna Silvestre Neotropical).

Mourão, G. \& Medri, M. 2007. Activity of a specialized insectivorous mammal (Myrmecophaga tridactyla) in the Pantanal of Brazil. Journal of Zoology, 271: 187-192.

Muñoz-Saba, Y.; Trujillo, F.; Calvo-Roa, N.; Cañón, S. \& Mosquera-Guerra, F. 2016. Mamíferos de las cuencas de los ríos Meta y Bita. In: Trujillo, F.; Antelo, R. \& Usma, S. (Eds.). Biodiversidad de la cuenca baja y media del río Meta. Bogotá, Fundación Omacha, Fundación Palmarito, WWF. p. 248-273. 
O'Brien, T.; Kinnaird, M. \& Wibisono, H. 2003. Crouching tigers, hidden prey: Sumatran tiger and prey populations in a tropical forest landscape. Animal Conservation, 6(2): 131-139.

Oehler, J.D.; Litvaitis, J.A. 1996. The role of spatial scale in understanding responses of medium-sized carnivores to forest fragmentation. Canadian Journal of Zoology, 74(11): 2070-2079.

Pardo, A. \& Rangel-Ch, J.0. 2014. Mamíferos de la Orinoquia. In: Rangel-Ch, J.0. (Ed.). Colombia Diversidad Biótica XIV. Bogotá, Universidad Nacional de Colombia. p. 751-784.

Pardo, L.E. \& Payán, E. 2015. Mamíferos de un agropaisaje de palma de aceite en las sabanas inundables de Orocué, Casanare, Colombia. Biota Colombiana, 16(1): 54-66.

Pardo, L.E.; Campbell, M.J.; Edwards, W.; Clements, G.R. \& Laurance, W.F. 2018a. Terrestrial mammal responses to oil palm dominated landscapes in Colombia. PLoS ONE, 13(5): e0197539.

Pardo, L.E.; Roque, F.de 0.; Campbell, M.J.;Younes, N.; Edwards, W. \& Laurance, W.F. 2018b. Identifying critical limits in oil palm cover for the conservation of terrestrial mammals in Colombia. Biological Conservation, 227: 65-73.

Pulido-Castelblanco, L.; Isaza-Narváez, C. \& Díaz-Pulido, A. 2017. Methodology for mammal classification in camera trap images. In: Proceedings of SPIE 10341, Ninth International Conference on Machine Vision (ICMV 2016). DOI

Ramírez-Chaves, H.; Suárez-Castro, A.F. \& González-Maya, J.F. 2016. Cambios recientes a la lista de los mamíferos de Colombia. Mammalogy Notes, 3(1): 1-9.

Redford, K.H. 1992. The empty forest. BioScience, 42(6): 412-422.

Redford, K.H.; Fonseca, G.A.B. 1986. The role of Gallery Forests in the Zoogeography of the Cerrado's non-volant Mammalian Fauna. Biotropica, 18(2): 126-135

Rippstein, G.; Amesquita, E.; Escobar, G. \& Grollier, C. 2001. Condiciones naturales de las sabanas. In: Rippstein, G.; Escobar, G. \& Motta F. (Eds.). Agroecología y Biodiversidad de las Sabanas de los Llanos Orientales. Cali, CIAT. p. 1-21.

Rodríguez-Mahecha, J.; Alberico, M.; Trujillo, F. \& Jorfenson, J. 2006. Red Book of Mammals of Colombia. Bogotá, International Conservation Colombia \& Ministry of Environment, Housing and Developmental Territory.

Rojano, C.; López-Giraldo, M.E.; Miranda-Cortés, L. \& Ávila-Avialán, R. 2015a. Área de vida y uso de hábitats de dos individuos de oso palmero
(Myrmecophaga tridactyla) en Pore, Casanare, Colombia. Edentata, 16: 37-45.

Rojano, C.; Padilla, H.; Giraldo, A.; Alvarez, G. \& Ramos, E. 2015b. Registro de presencia del oso palmero (Myrmecophaga tridactyla) en plantaciones forestales comerciales en Colombia. Edentata, 16: 72-77.

Romero, M.; Galindo, G.; Otero, J. \& Armenteras, D. 2004. Ecosistemas de la cuenca del Orinoco Colombiano. Bogotá, Instituto Alexander Von Humboldt.

Romero-Ruiz, M.; Etter, A.; Sarmiento, A. \& Tansey, K. 2010. Spatial and temporal variability of fires in relation to ecosystems, land tenure and rainfall in savannas of northern South America. Global Change Biology, 16(7): 2013-2023.

Romero-Ruiz, M.H.; Flantua S.G.A.; Tansey K. \& Berrio, J.C. 2011. Landscape transformations in savannas of northern South America: Land use/ cover changes since 1987 in the Llanos Orientales of Colombia. Applied Geography, 32: 766-776.

Sarmiento, G. 1983. The savannas of tropical America. In: Bourliere, F. (Ed.). Ecosystems of the World XIII Tropical savannas. Amsterdam, Elsevier. p. 254-288.

Sobral, M.; Silvius, K.M.; Overman, H.; Oliveira, L.F.B. \& Rabb, T.K. 2017. Mammal diversity influences the carbon cycle through trophic interactions in the Amazon. Nature Ecology \& Evolution, 1: 1670-1676.

Solari, S.; Muñoz-Saba, Y.; Rodríguez-Mahecha, J.V.; Defler, T.; RamírezChaves, H.E. \& Trujillo, F. 2013. Riqueza, endemismo y conservación de los mamíferos de Colombia. Mastozoología Neotropical, 20(2): 301-365.

Steiner, K.E. 1981. Nectarivory and Potential Pollination by a Neotropical marsupial. Annals of the Missouri Botanical Garden, 68(4): 505-513.

Suárez-Castro, A.F. \& Ramírez-Chaves, H.E. 2015. Los carnívoros terrestres y semiacuáticos continentales de Colombia. Guía de Campo. Bogotá Editorial Universidad Nacional de Colombia.

Terborgh, J.; López, L.; Nunez, P.; Rao, M.; Shahabuddin, G.; Orihuela, G.; Riveros, M.; Ascanio, R.; Adler, G.H.; Lambert, T.D. \& Balbas, L. 2001. Ecological meltdown in predator-free forest fragments. Science, 294(5548): 1923-1926.

Trujillo, C.W. \& Henáo-Cárdenas, M.M. 2018. Riqueza florística y recambio de especies en la vertiente orinoquense de los Andes, Colombia. Colombia Forestal, 21(1): 18-33. 